\title{
Heavy Metal Ion Immobilization Properties of Microporous Ettringite Body
}

\author{
Hyeon Yeop Na and Tae Woong Song ${ }^{\dagger}$ \\ Department of Advanced Materials Engineering, Kyungnam University, Masan 631-701, Korea \\ (Received November 12, 2009; Revised November 19, 2009; Accepted November 20, 2009)
}

\section{에트린자이트 미세다공체의 중금속 이온 고정화 특성

\author{
나현엽 · 송태웅 \\ 경남대학교 신소재공학과 \\ (2009년 11월 12일 접수 ; 2009년 11월 19일 수정 ; 2009년 11월 20일 승인)
}

\begin{abstract}
Heavy metal ion immobilization properties of microporous ettringite $\left(3 \mathrm{CaO} \cdot \mathrm{Al}_{2} \mathrm{O}_{3} \cdot 3 \mathrm{CaSO}_{4} \cdot 32 \mathrm{H}_{2} \mathrm{O}\right)$ body were examined using standard solutions of typical heavy metals. Microporous Ettringite body with desirable shape for an ionic adsorbent was obtained by the self hardening of the paste prepared from the mixture of tricalcium aluminate $\left(\mathrm{C}_{3} \mathrm{~A}\right)$ and gypsum $\left(\mathrm{CaSO}_{4} \cdot 2 \mathrm{H}_{2} \mathrm{O}\right)$. Crushed grains of ettringite were soaked in each standard solutions of $\mathrm{Pb}, \mathrm{Co}, \mathrm{Cd}, \mathrm{Mn}$ and $\mathrm{Cr}$ concentrated at $200 \mathrm{ppm}$. In order to evaluate the ionexchange and immobilization ability, the ionic concentration of the filtrate solution as well as the solution obtained after leaching test was measured. As a result, for the heavy metal ions excepting $\mathrm{Cr}$, porous ettringite body was revealed to be excellent in ionic exchange and immobilization properties though some ions eluted at the severe condition of $\mathrm{pH} 2$. The adsorption and keeping capacity for four heavy metals showed the order of $\mathrm{Pb}>\mathrm{Co}>\mathrm{Cd}>\mathrm{Mn}$.
\end{abstract}

Key words : Tricalciumaluminate, Ettringite, Heavy metal ion, Immobliization, Dissolution

\section{1. 서 론}

칼슘설포알루미네이트계 광물의 하나인 에트린자이트 (Ettringite, $3 \mathrm{CaO} \cdot \mathrm{Al}_{2} \mathrm{O}_{3} \cdot 3 \mathrm{CaSO}_{4} \cdot 32 \mathrm{H}_{2} \mathrm{O}$ )는 다량의 물 분자 를 함유하는 막대상의 고팽창성 수화물로서, 그 용도는 주로 시멘트의 수화 중에 생성되도록 하여 시멘트에 팽 창성, 속경성 또는 조강성을 부여하거나 고강도를 발현하 는데 이용되고 있다. ${ }^{1,2)}$ 그러나 환경 문제가 고조됨에 따 라 최근에는 에트린자이트의 새로운 용도로 이의 화학조 성과 결정학적 특징을 이용한 중금속 이온 흡착소재로서 의 활용이 제시되었다. ${ }^{3-7)}$ 이는 $\mathrm{Ca}_{6}\left[\mathrm{Al}(\mathrm{OH})_{6}\right]_{2}\left(\mathrm{SO}_{4}\right)_{3} \cdot 3 \mathrm{H}_{2} \mathrm{O}$ 의 구조식에서 볼 수 있는 바와 같이 에트린자이트가 다 양한 중금속의 이온 또는 착이온과 치환될 수 있는 $\mathrm{Ca}^{2+}$, $\mathrm{SO}_{4}^{2-}, \mathrm{Al}^{3+}$ 및 $\mathrm{OH}$ 로 구성되어 있다는 화학적 특성과, 결 정의 $\mathrm{C}$ 축 방향으로 이온들의 이동에 충분한 크기의 채널 이 형성되어 있다는 구조적 특성을 응용하고자 하는 것 이다. 그러나 이를 중금속 이온 제거재로서 실용화하기 위한 연구나 특허는 환경문제의 중요성에 비하여 아직 활

\footnotetext{
${ }^{\dagger}$ Corresponding author : Tae Woong Song

E-mail : twsong@kyungnam.ac.kr

Tel : +82-55-249-2695 Fax : +82-55-248-5033
}

발하지 못한 상태이며, 이는 에트린자이트만으로 이루어 지고 submicron 크기의 많은 공극과 적절한 강도를 가진 미세다공체를 얻기가 쉽지 않았기 때문으로 보인다. 본 연구는 서로 얽힌 상태에서 막대상 결정이 성장하도록 하 여 에트린자이트 미세다공체를 얻는 연구 ${ }^{8)}$ 에 후속한 것 으로서, 몇 가지 중금속 이온 각각에 대한 이 재료의 실 질적인 고정화 능력을 확인하고자 한 기초 연구이다.

\section{2. 실험 방법}

에트린자이트 다공체는 선행 연구결과에 따라 다음과 같이 합성하였다. 먼저 $\mathrm{CaO}: \mathrm{Al}_{2} \mathrm{O}_{3}$ 몰 비가 $3: 1$ 조성인 혼 합물을 1 차 소성하여 $\mathrm{CaO}-\mathrm{Al}_{2} \mathrm{O}_{3}$ 계 다광물 클링커를 만든 후 이를 분쇄, 수화시켜 얻은 경화체를 재소성하는 방법 ${ }^{9)}$ 으로 단일 상의 $3 \mathrm{CaO} \cdot \mathrm{Al}_{2} \mathrm{O}_{3}$ (tricalcium aluminate, $\mathrm{C}_{3} \mathrm{~A}$ ) 클링커를 얻었다. 다음에는 이 $\mathrm{C}_{3} \mathrm{~A}$ 의 분말에 이수석고 $\left(\mathrm{CaSO}_{4} \cdot 2 \mathrm{H}_{2} \mathrm{O}\right)$ 를 에트린자이트 조성이 되도록 조합하여 $24^{\circ} \mathrm{C}$, 물/분말 비 1 의 조건으로 24 시간 동안 수화·양생시 켜) 에트린자이트 다공체를 합성하였다. 중금속 이온 제 거능 시험에는 이 다공체를 파쇄하여 얻은 직경 $0.5 \sim 1 \mathrm{~mm}$ 정도의 알갱이를 시료로 사용하였으며 중금속 용액은 Kanto Co., Inc.에서 제조한 $1000 \mathrm{ppm}$ 농도의 납, 카드뭄, 


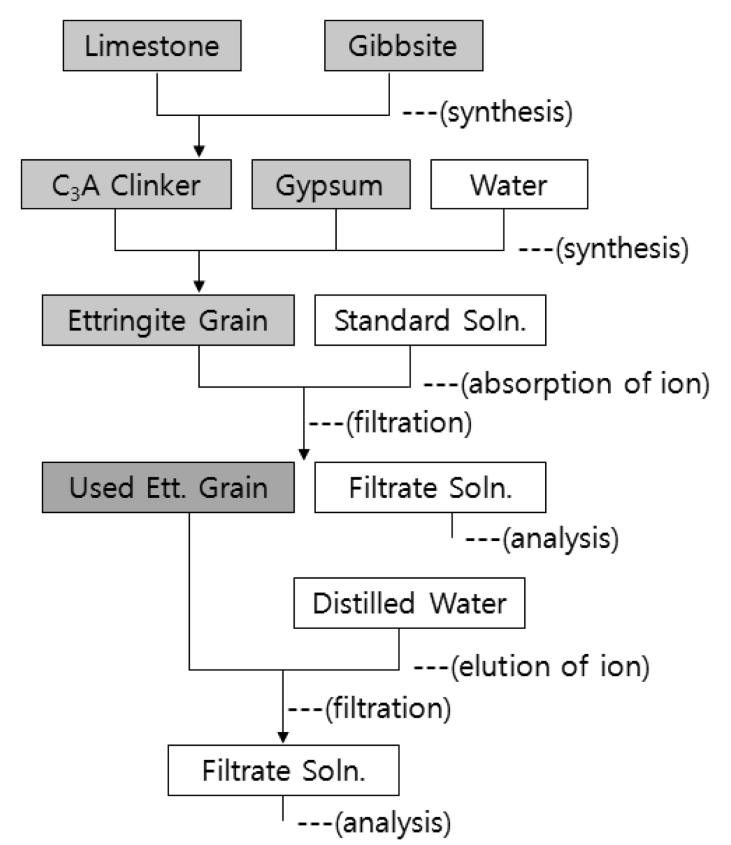

Fig. 1. Schematic diagram for experimental procedure.

코발트, 망간 및 크롬 표준용액을 각각 $200 \mathrm{ppm}$ 으로 희 석하여 시험용액으로 사용하였다. 중금속 이온 제거능 시 험은 상온의 시험용액 $50 \mathrm{ml}$ 에 $0.1 \sim 2 \mathrm{~g}$ 범위의 에트린자 이트 알갱이를 넣고 일정시간 동안 교반한 후 알갱이를 여과해 낸 용액의 중금속 이온의 농도를 원자흡수분광광 도계로 측정하는 방법으로 실시하였으며 이때 용액의 $\mathrm{pH}$ 변화를 측정하여 참고자료로 하였다. 다음에는 에트린자 이트로부터의 중금속 이온의 재용출 특성을 시험하기 위 하여 용액에서 여과·분리된 에트린자이트 알갱이를 에트 린자이트 $1 \mathrm{~g}$ 당 $50 \mathrm{ml}$ 에 해당하는 증류수에 투입하고 6 24분 동안 시간을 달리하여 교반한 후 증류수 중의 용 출 이온의 농도를 측정하였다. 한편 증류수에 염산을 가 하여 $\mathrm{pH}$ 를 임의로 조절한 후 동일한 시험을 실시함으로 써 재용출 거동에 미치는 $\mathrm{pH}$ 의 영향도 확인하였다. 이상 과 같은 실험방법의 순서도는 Fig. 1 과 같다.

\section{3. 결과 및 고찰}

\section{1. 에트린자이트 다공체의 특성}

Fig. 2는 에트린자이트 다공체의 광물상과 파단면의 미 세구조를 나타낸 것이다. 그림에서 보는 바와 같이 본 연 구에서 중금속 이온 제거능 시험용으로 사용한 시료는 거 의 순수한 에트린자이트로 이루어져 있으며, 막대상의 에 트린자이트 결정이 서로 다른 배향으로 얽힌 상태에서 평 균 직경 약 $0.2 \mu \mathrm{m}$, 길이 $1 \sim 2 \mu \mathrm{m}$ 까지 성장하여 비교적 균 질한 다공성 벌크체를 형성하였음을 알 수 있다. 이 다공 체는 submicron 크기의 무수한 공극으로 인하여 약 $33 \%$
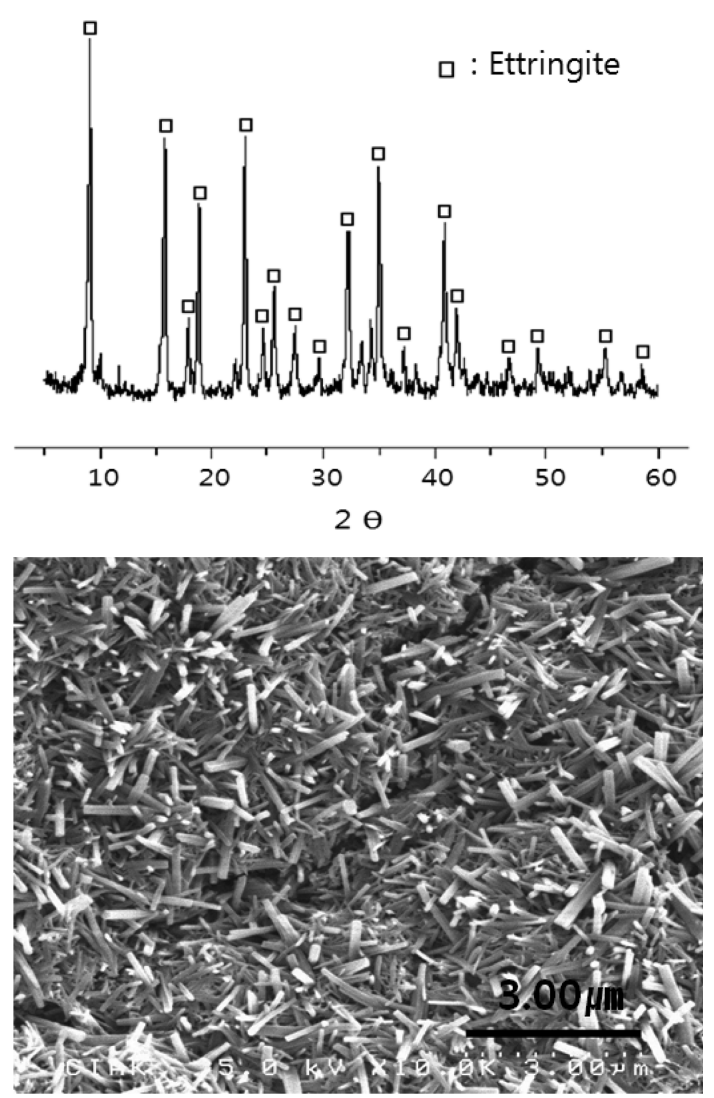

Fig. 2. XRD pattern and SEM microphotograph of microporous ettringite body prepared by hydration at $24^{\circ} \mathrm{C}$ for $24 \mathrm{~h}(\mathrm{~W} / \mathrm{P}=1.0)$.

의 기공률에 비표면적이 $38.48 \mathrm{~m}^{2} / \mathrm{g}$ 에 달하는 것으로 확 인되었으며 내수성과 적정의 강도를 가져 수중 이온의 제 거용으로 매우 적합한 성상을 나타내었다.

\section{2. 에트린자이트의 중금속 이온 치환 특성}

\subsection{1. 중금속 이온 치환능}

다섯 종류의 중금속 표준용액에 대한 에트린자이트의 이온 제거능을 시험한 결과를 Fig. 3에 나타내었다. 이는 기초실험의 결과에 따라 에트린자이트의 투입량을 용액 $50 \mathrm{ml}$ 당 $0.1 \mathrm{~g}$ 부터 $2 \mathrm{~g}$ 까지 달리하고 침지시간을 60 분으 로 하여 얻은 결과이다. 이 결과에 따르면 납, 코발트 및 카드뮴 이온은 $1 \mathrm{~g}$ 의 에트린자이트의 투입에 의하여 전량 이 제거되었으며 망간은 전량을 제거하는 데 약 $1.5 \mathrm{~g}$ 의 에트린자이트가 필요한 것을 알 수 있다. 그러나 크롬의 경우에는 에트린자이트 투입량 $1 \mathrm{~g}$ 까지는 이온 농도가 약 간 감소하기는 하나 그 이상으로는 투입량을 늘여도 농 도가 거의 감소되지 않음으로서 타 이온과 달리 에트린 자이트에 의한 제거 효율이 극히 미약함을 알 수 있다. Fig. 4는 에트린자이트가 담지된 각종 용액의 $\mathrm{pH}$ 변화를 시간 경과에 따라 측정한 결과이다. 에트린자이트는 용해 도적 $\left(\mathrm{K}_{\mathrm{sp}}\right)$ 이 $1.1 \times 10^{-40}$ 으로서 ${ }^{10)}$ 매우 작아 물에 거의 용해 


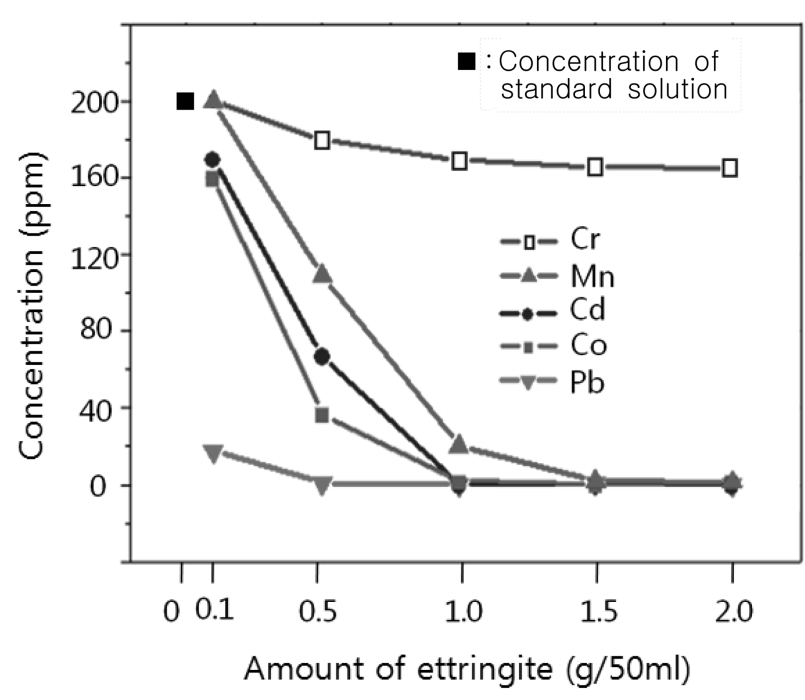

Fig. 3. Concentration of heavy metal ion measured at $60 \mathrm{~min}$ after addition of different amount of ettringite.

하지 않지만 증류수의 $\mathrm{pH}$ 를 약간 상승시키는 것이 확인 되어 증류수에서도 약간의 $\mathrm{Ca}^{2+}$ 가 용출되고 있음을 알 수 있다. 그러나 중금속 용액은 $\mathrm{pH}$ 상승 폭이 매우 크게 나 타났는데, 이는 에트린자이트에 의한 $\mathrm{Ca}^{2+}$ 의 용출과 양이 온 $\left(\mathrm{Pb}^{2+}, \mathrm{Co}^{2+}, \mathrm{Cd}^{2+}\right.$ 및 $\left.\mathrm{Mn}^{3+}\right)$ 의 치환흡착에 따른 것이라 고 보인다. 이들 이온은 $\mathrm{pH} 9$ 이하에서는 수산화물을 형 성할 수 없으므로 농도의 저하는 주로 에트린자이트의 화 학흡착에 기인한다고 할 수 있으며, 이온의 크기와 전하 그리고 에트린자이트 구조의 size limitation ${ }^{10}$ 을 고려하면 납, 코발트 및 카드뭄은 에트린자이트의 $\mathrm{Ca}^{2+}$ 와, 망간은 에트린자이트의 $\mathrm{Al}^{3+}$ 와 각각 치환된 것으로 사료된다. 크 롬(VI)의 경우 표준용액의 농도 $(200 \mathrm{ppm})$ 와 $\mathrm{pH}(3.7)$ 에서 존재하는 이온종은 $\mathrm{HCrO}_{4}^{-}$가 대부분을 차지하고 $\mathrm{pH}$ 4부 터는 $\mathrm{CrO}_{4}{ }^{2-}$ 로 변하기 시작하여 $\mathrm{pH} 8$ 이상에서는 모두 $\mathrm{CrO}_{4}^{2-}$ 로 존재하는 것으로 알려져 있다. 크롬의 이 두 가 지 이온종은 에트린자이트의 생성 시에는 구성 이온으로 들어가 chromate ettringite를 형성할 수는 있으나 ${ }^{10)}$ 이때 $\mathrm{SO}_{4}^{2-}$ 가 공존하면 $\mathrm{CrO}_{4}{ }^{2-}$ 보다 $\mathrm{SO}_{4}{ }^{2-}$ 가 우선적으로 에트린 자이트를 만드는 것으로 밝혀졌다. 이러한 이유로 본 연 구에서와 같이 이미 만들어진 에트린자이트의 $\mathrm{SO}_{4}{ }^{2-}$ 자 리에 이러한 크롬의 이온종이 치환되기가 어려웠던 것으 로 해석된다. 크롬용액에서도 $\mathrm{pH}$ 가 크게 상승된 것은 표 준용액의 산성도에 의한 에트린자이트의 용해에 따른 $\mathrm{Ca}^{2+}$ 용출이 주원인일 것으로 사료된다. 이상에서 고찰한 바와 같이 다섯 가지 이온 각각의 표준용액을 사용한 실험에 서 본 연구의 에트린자이트 다공체는 $\mathrm{Cr}$ 을 제외하고는 $\mathrm{Pb}$ $>\mathrm{Co}>\mathrm{Cd}>\mathrm{Mn}$ 의 순서로 우수한 치환흡착능을 나타내며 농도 $200 \mathrm{ppm}$ 의 용액 $50 \mathrm{ml}$ 중의 이온을 모두 제거하는 데 필요한 양은 $\mathrm{Pb}, \mathrm{Co}$ 및 $\mathrm{Cd}$ 의 경우에는 $1 \mathrm{~g}, \mathrm{Mn}$ 의 경 우에는 $1.5 \mathrm{~g}$ 인 것으로 나타났다.

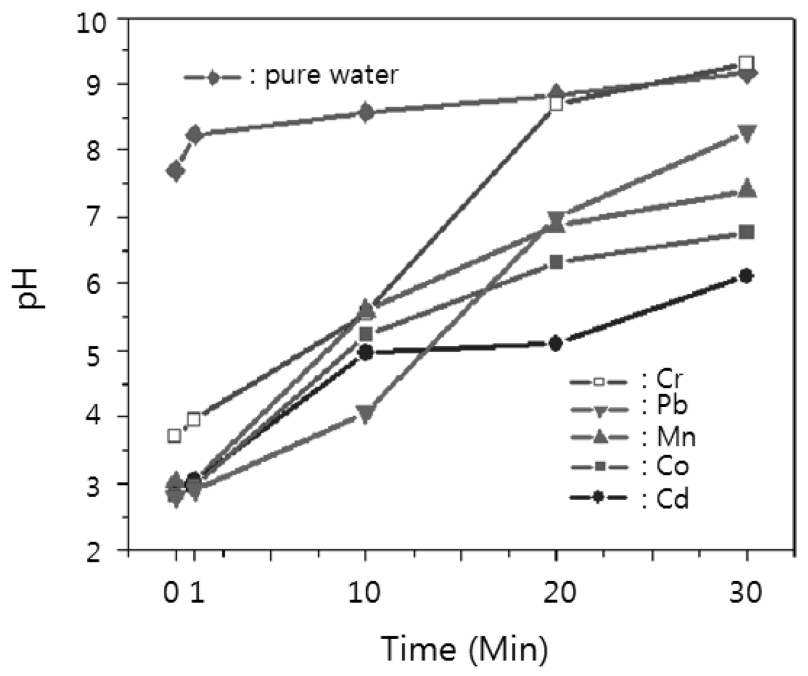

Fig. 4. The change in solution $\mathrm{pH}$ with time during the adsorption function of ettringite.

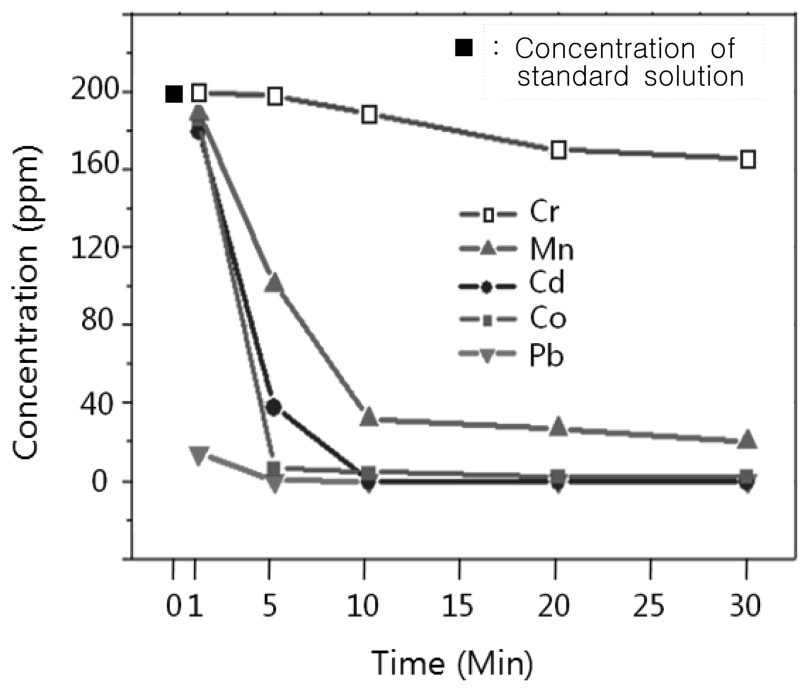

Fig. 5. Decrease in concentration of heavy metal ion with time by the adsorption function of ettringite.

\subsection{2. 중금속 이온 치환 속도}

앞에서 얻은 결과를 참조하여 $200 \mathrm{ppm}$ 의 중금속 용액 $50 \mathrm{ml}$ 에 각각 $1 \mathrm{~g}$ 씩의 에트린자이트를 투입하고 교반 시 간을 달리하여 측정한 이온의 농도를 Fig. 5 에 나타내었 다. 이 결과로부터 납과 코발트는 5 분 이내에, 카드뮴 이 온은 약 10 분에서 거의 전량이 제거되었고 $\mathrm{Al}^{3+}$ 와 치환하 는 것으로 생각되는 망간의 경우는 제거 속도가 다소 느 려 10 분에서 약 $80 \%$ 가 제거됨으로서 에트린자이트가 이 들 이온에 대해서는 우수한 제거능을 가지며 제거속도는 납>코발트>카드뮴>망간 순인 것으로 나타났다. 크롬의 경우엔 30 분 후의 제거율이 약 $20 \%$ 이하로서 상당히 낮 은 결과를 보였다. 시간 경과에 따른 중금속 이온의 농도 감소 속도는 대체적으로 Fig. 3에 나타낸 에트린자이트 


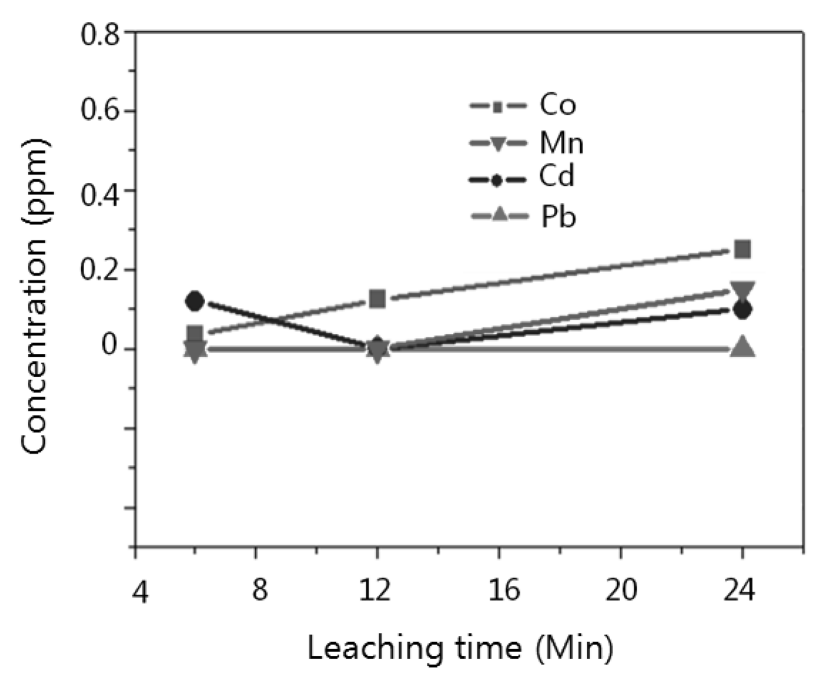

Fig. 6. Concentration of heavy metal ion leached from ettringite at various digestion time.

중량당의 제거능과 일치하는 순서를 나타내었으며 크롬 을 제외한 4종의 중금속 이온에 대해 우수한 제거능과 제 거 속도를 나타내었다.

\section{3. 중금속 이온의 재용출 특성}

\subsection{1. 시간 경과에 따른 재용출 특성}

Fig. 6은 앞의 실험에서 크롬을 제외한 나머지 중금속 을 각각 흡착한 4종의 에트린자이트 알갱이를 일정량의 증류수에 침지하여 6 24분 동안 교반한 후 해당 이온의 용출 농도를 측정한 결과를 나타낸 것이다. 이 결과는 우 선 모든 시료에서 재용출이 거의 일어나지 않음을 보여 준다. 납은 전혀 재용출이 없고, 그 밖의 이온은 종류에 따라 미소한 차이는 있지만 $200 \mathrm{ppm}$ 농도의 용액 $50 \mathrm{ml}$ 중에 존재하던 이온을 10 분 내에 모두(망간의 경우 약 $80 \%$ ) 흡착한 에트린자이트임을 감안하면 약 $0.2 \mathrm{ppm}$ 정 도의 용출은 무시할 수 있는 양이라고 사료된다. 이러한 결과는 에트린자이트의 중금속 이온 흡착이 물리흡착이 아닌 화학흡착으로서, 앞에서 고찰한 바와 같이 중금속 제거는 이온 교환에 의해 일어난다는 것을 입증하는 것 이라고 사료된다.

\subsection{2. $\mathrm{pH}$ 에 따른 재용출 특성}

Fig. 7은 염산으로 증류수의 $\mathrm{pH}$ 를 변화시킨 후 용출 시 간을 6시간으로 늘여 앞에서와 같은 방법으로 용출 이온 의 농도를 측정한 결과를 나타낸 것이다. 이 결과에 따르 면 $\mathrm{pH}$ 4에서부터 점차 이온이 용출되기 시작하여 $\mathrm{pH} 2$ 에서는 망간과 카드뮴의 경우 흡착되었던 양의 약 $17 \%$ 정도가 용출되며 납과 코발트도 3 5\% 정도 용출됨을 확 인할 수 있다. 이는 $\mathrm{pH}$ 가 낮아짐으로서 염기성광물인 에 트린자이트가 분해하면서 치환되어 있던 중금속 이온이

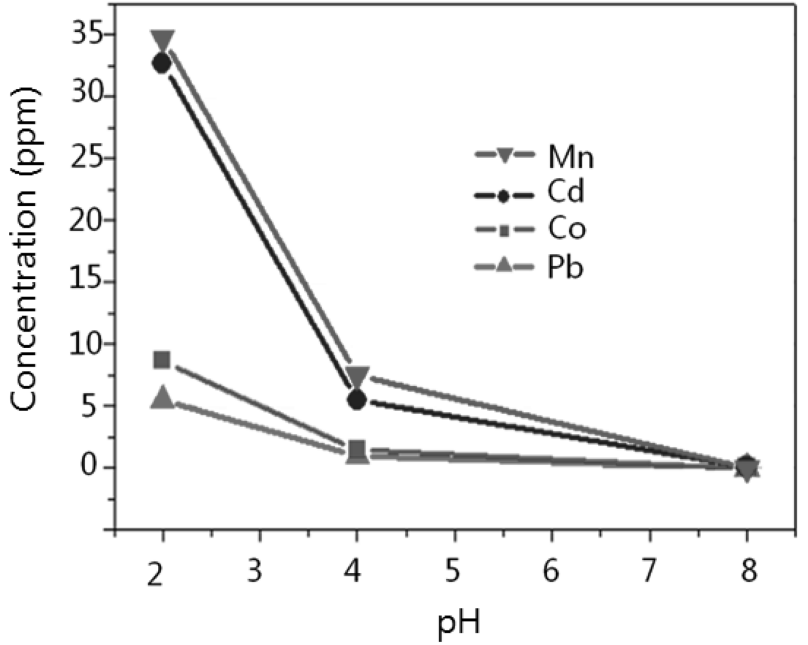

Fig. 7. Concentration of heavy metal ion leached from ettringite for $6 \mathrm{~h}$ at various $\mathrm{pH}$ of solutions.

다시 용출되는 것이 주된 원인일 것으로 보이나, 치환 이 온의 크기와 위치 및 일부 물리흡착된 이온의 존재량 등 도 복합적으로 작용했을 것으로 사료된다. 그러나 $\mathrm{pH} 2$ 에서 6시간 동안 교반한 가혹한 용출 조건에 비하면 용 출양이 적은 편으로 평가됨으로서 본 실험에서 사용한 에 트린자이트 다공체는 중금속 제거를 위한 환경소재로서 의 활용가능성이 매우 큼을 확인할 수 있다.

이 결과로 부터 에트린자이트 다공체는 제거효율이 높 고, 용출 특성을 확인하기 위한 몇 가지의 조건변화에 따 른 실험에서도 낮은 용출량을 보임으로서 중금속 제거를 위한 환경소재로서의 활용가능성이 매우 큼이 확인되었다.

\section{4. 결 론}

수화물 소성법으로 합성한 $\mathrm{C}_{3} \mathrm{~A}$ 클링커에 이수석고를 혼합하여 만든 페이스트가 스스로 경화하여 형성된 에트 린자이트 미세다공체는 중금속 제거용 환경소재로서의 응 용성이 매우 큰 것으로 확인되었다. 납, 코발트, 카드뮴 및 망간의 표준용액을 각각 사용한 시험에서 에트린자이 트 다공체는 이온 치환에 의한 화학흡착으로 매우 신속 하고 우수한 이온 제거능을 나타내었으며 흡착된 이온은 중성의 수중에서 거의 재용출되지 않음이 확인되었다. 그 러나 매우 낮은 $\mathrm{pH}$ 에서는 어느 정도의 재용출을 피할 수 없으며 6가 크롬에 대해서는 용존하는 이온종의 특성 상 이러한 흡착 성능이 거의 나타나지 않음을 확인하였다.

\section{Acknowledgment}

본 연구는 2008학년도 2학기 경남대학교 교내 학술진흥 연구비의 지원에 의해 이루어졌으므로 이에 감사드립니다. 


\section{REFERENCES}

1. H. F. W. Taylor, The Chemistry of Cement, pp. 168-283, Academic Press Inc., London, 1979.

2. F. M. Lea, The Chemistry of Cement and Concrete, pp. 177249, Chemical Publishing Co, Inc., New York, 1971.

3. G. J. McCarthy, D. J. Hassett, and J. A. Bender, "Synthesis, Crystal Chemistry and Stability of Ettringite, a Material with Potential Applications in Hazardous Waste Immobilization," Advanced Cementitious Systems: Mechanisms and Properties, Materials Research Society Symposium Proceedings, 245 129-49 (1992).

4. M. L. D. Gougar, B. E. Scheetz, and D. M. Roy, "Ettringite and C-S-H Portland Cement Phases for Waste Ion Immobilization," Waste Management, 16 [4] 295-303 (1996).

5. V. Albino, R. Cioffi, M. Marroccoli, and L. Santoro, "Potential Application of Ettringite Generating Systems for Hazardous Waste Stabilization," Journal of Hazardous Materials., 51 241-52 (1996).

6. M. Zhang and E. J. Reardon, "Removal of B, Cr, Mo and Se from Wastewater by Incorporation into Hydrocalumite and Ettringite, Environmental," Science \& Technology, 37 [13] 2947-52 (2003).

7. D. Bonen and S. L. Sarkar, "The Present State-of-the-art of Immobilization of Hazardous Heavy Metals in cEmentbased Materials," pp. 481-98, Advances Cem. \& Concr., Proceedings of an Engineering Foundation Conference(edited by Michael W. Grutzeck and Shondeep L. Sarkar), American Society of Civil Engineers, New York, 1994.

8. H. Y. Na and T. W. Song, "Formation Behavior of Microporous Ettringite Body by Hydration of Tricalciumaluminate Clinker and Gypsum," J. Kor. Ceram. Soc., 45 [11] 734-38 (2008).

9. T. K. Ki and T. W. Song, "Study on Synthesis of Tricalciumaluminate Clinker by Hydrate-burning Method," $J$. Kor. Ceram. Soc., 44 [9] 517-23 (2007).

10. J. Bensted and S. Pracashi Varma, "Studies of Ettringite and its Derivatives, Part 2: Chromate Substitution," Silicate Industries, 37 [12] 315-18 (1972). 